ERNEST DRLANDQ LAWRENEE BERRELEY NATIDNAL LABGRATURY

\title{
Development of an Accelerator-Based BNCT Facility at the Berkeley Lab
}

B.A. Ludewigt, D.L. Bleuel, W.T. Chu, R.J. Donahue, J. Kwan, L.L. Reginato, and R.P. Wells

\section{Accelerator and Fusion Research Division}

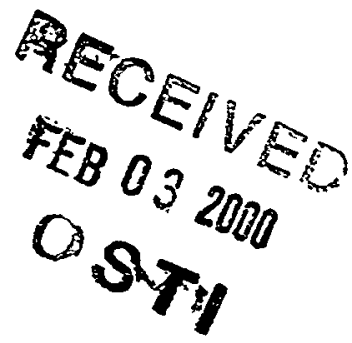

March 1998

Presented at the 8th International Symposium on Neutron Capture Therapy for Cancer, Los Angeles, CA, September 13-18, 1998, and to be published in the Proceedings
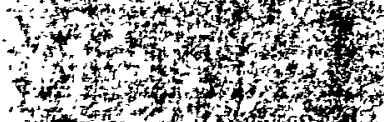

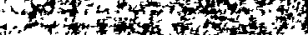
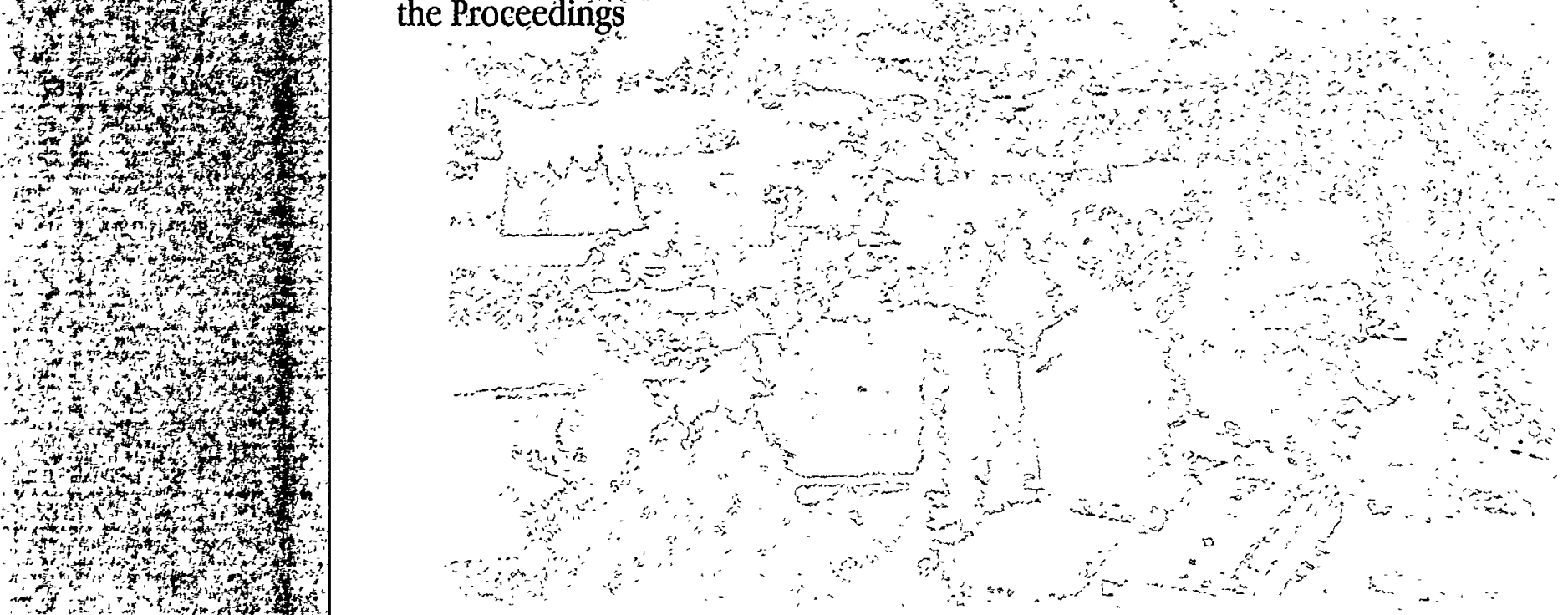


\section{DISCLAIMER}

This document was prepared as an account of work sponsored by the United States Government. While this document is believed to contain correct information, neither the United States Government nor any agency thereof, nor The Regents of the University of California, nor any of their employees, makes any warranty, express or implied, or assumes any legal responsibility for the accuracy, completeness, or usefulness of any information, apparatus, product, or process disclosed, or represents that its use would not infringe privately owned rights. Reference herein to any specific commercial product, process, or service by its trade name, trademark, manufacturer, or otherwise, does not necessarily constitute or imply its endorsement, recommendation, or favoring by the United States Government or any agency thereof, or The Regents of the University of California. The views and opinions of authors expressed herein do not necessarily state or reflect those of the United States Government or any agency thereof, or The Regents of the University of California. 


\section{DISCLAIMER}

Portions of this document may be illegible in electronic image products. Images are produced from the best available original document. 
LBNL-41669

\title{
Development of an Accelerator-Based BNCT Facility at the Berkeley Lab
}

\author{
B.A. Ludewigt, D.L. Bleuel, W.T. Chu, R.J. Donahue, \\ J. Kwan, L.L. Reginato, and R.P. Wells \\ Accelerator and Fusion Research Division \\ Ernest Orlando Lawrence Berkeley National Laboratory \\ University of California \\ Berkeley, California 94720
}

March 1998

This work was supported by the Director, Office of Energy Research, of the U.S. Department of Energy under Contract No. DE-AC03-76SF00098. 


\title{
Development of an Accelerator-Based BNCT Facility at the Berkeley Lab
}

\author{
B.A. Ludewigt, D. L. Bleuel, W.T. Chu, R.J. Donahue, J. Kwan, L.L. \\ Reginato, and R.P. Wells \\ Ernest Orlando Lawrence Berkeley National Laboratory, Berkeley, CA \\ 94720
}

\begin{abstract}
An accelerator-based BNCT facility is under construction at the Berkeley Lab. An electrostatic-quadrupole (ESQ) accelerator is under development for the production of neutrons via the ${ }^{7} \mathrm{Li}(\mathrm{p}, \mathrm{n})^{7} \mathrm{Be}$ reaction at proton energies between 2.3 and $2.5 \mathrm{MeV}$. A novel type of power supply, an aircore coupled transformer power supply, is being built for the acceleration of beam currents exceeding $50 \mathrm{~mA}$. A metallic lithium target has been developed for handling such high beam currents. Moderator, reflector and neutron beam delimiter have extensively been modeled and designs have been identified which produce epithermal neutron spectra sharply peaked between 10 and $20 \mathrm{keV}$. These -neutron beams are predicted to deliver significantly higher doses to deep seated brain tumors, up to $50 \%$ more near the midline of the brain, than is possible with currently available reactor beams. The accelerator neutron source will be suitable for future installation at hospitals.
\end{abstract}

This work is supported by the Director, Office of Energy Research of the U.S. Department of Energy under Contract No. DE-AC03-76SF00098. 


\section{INTRODUCTION}

The clinical success of boron neutron capture therapy (BNCT) depends on both the selective concentration of the boron carrying drug in the tumor cells and the quality of the available neutron beam. For the treatment of glioblastoma multiforme (GBM) the ability of the neutron beam to deeply penetrate is of great importance.

At Berkeley Lab an accelerator-based neutron source is being developed which will deliver neutron beams optimized for their clinical application and suitable for deployment at hospitals. The goal of the BNCT program at Berkeley Lab is to construct an acceleratorbased BNCT facility and to make it available for clinical trials to be conducted in collaboration with the UCSF Cancer Center. Important progress has been made over the past 2 years. Neutronics studies have been performed to determine accelerator and target requirements and to predict the quality and the clinical attributes of the neutron beam. The work on the two most critical components, the neutron production target and the accelerator power supply, has reached an advanced state.

\section{ACCELERATOR-BASED BNCT FACILITY}

The combination of unique accelerator expertise, past experience in high-LET radiotherapy, and the availability of a shielded treatment room provide an excellent opportunity for developing and constructing an accelerator-based BNCT facility at Berkeley Lab. After evaluating a number of nuclear reactions and accelerator options ${ }^{1}$ we

chose the ${ }^{7} \mathrm{Li}(\mathrm{p}, \mathrm{n}){ }^{7} \mathrm{Be}$ reaction at proton energies between 2.3 and $2.5 \mathrm{MeV}$ for the neutron production. The low primary neutron energies from this reaction help to produce epithermal neutron beams with near optimal energy spectra.

In the BNCT facility under construction, the proton beam will be generated by an electrostatic quadrupole accelerator capable of producing a proton beam current of $50 \mathrm{~mA}$. The beam is than guided through the beam transport line into the treatment room where it impinges on the neutron production target. The target consists of a $90 \mu \mathrm{m}$ thin layer of lithium deposited on a metal cooling backing. It is followed by the moderator. Both, moderator and target, are surrounded by reflector material for preventing neutrons not going forward from escaping and reflecting them back towards the patient. A delimiter placed between the moderator-reflector assembly and the patient defines the neutron beam diameter and shields the patients from unwanted radiation. Starting from clinical requirements for the treatment of deep-seated brain tumors we have optimized the epithermal neutron beam and determined the required proton current and other beam parameters ${ }^{2}$.

\section{HIGH CURRENT PROTON ACCELERATOR}

An accelerator which can produce a high proton beam current is essential for achieving high quality neutron beams and short treatment times. Over the last decade a special dcaccelerator, the electrostatic-quadrupole (ESQ) accelerator, has been developed for the heavy ion fusion program at Berkeley Lab. This dc-accelerator features a column of electrostatic quadrupoles instead of thick apertures and is ideally suited to produce very high-current ion beams in the desired energy range ${ }^{3}$. The focussing field in this structure is 
decoupled from the axially accelerating field making it possible to achieve strong focussing without exceeding the axial breakdown limit. Furthermore, the strong transverse field prevents electrons from streaming downstream and causing arc-downs. A cross section of the accelerator indicating the 13 module ESQ-column and the power supply structure is schematically shown in figure 1.

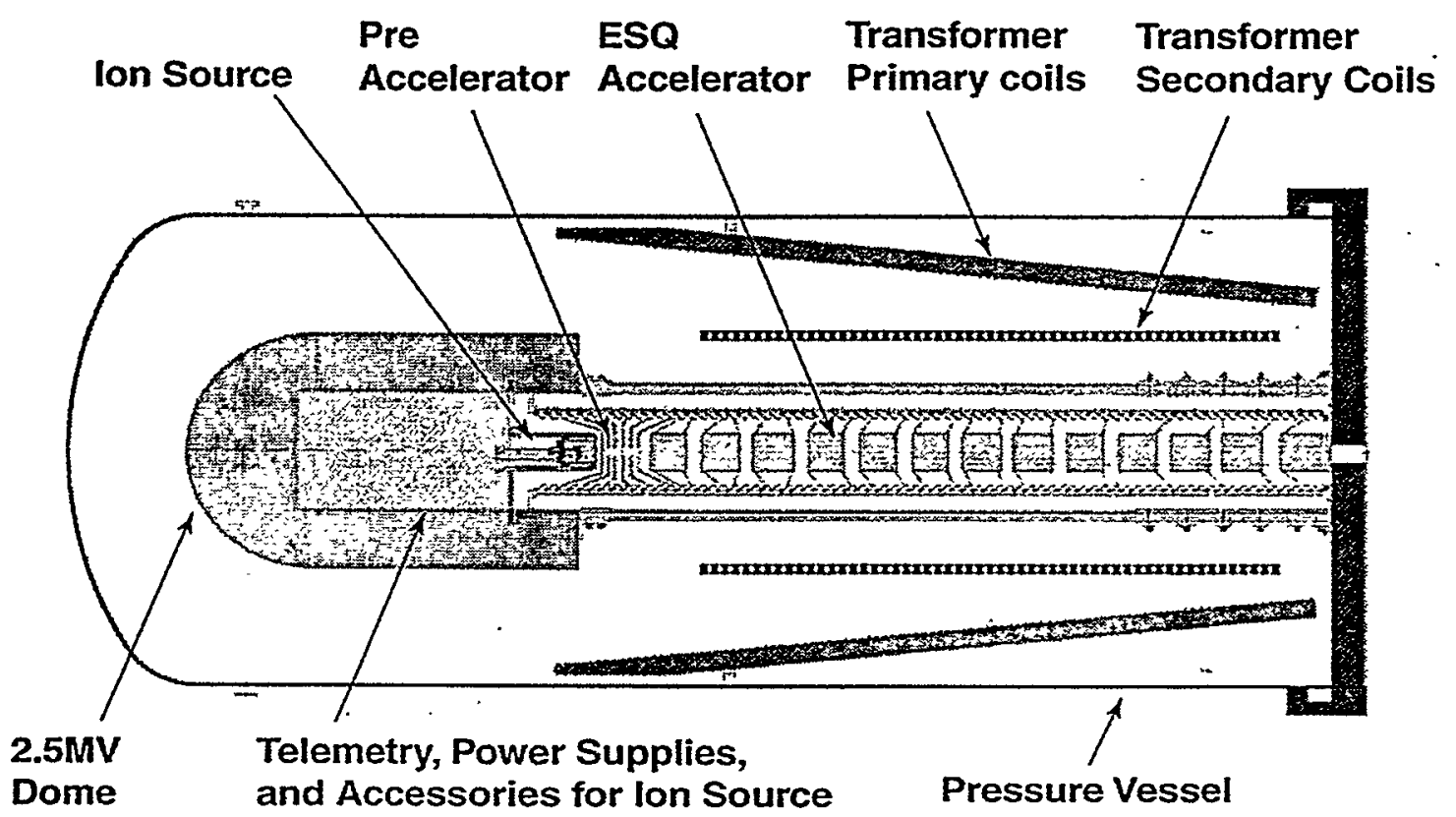

Fig. 1. Cross section of $2.5 \mathrm{MeV}, 50 \mathrm{~mA}$ ESQ-accelerator.

In addition to the acceleration column itself, the power supply is crucial for accelerating the desired beam currents. Because it would be difficult to generate tens of $\mathrm{mA}$ using a conventional, capacitively-coupled power supply, a new type of power supply is being developed and built. It is based on the concept of an air-core coupled transformer ${ }^{4}$. As can be seen in figure 1 a primary coil and 55 secondary coils supplying high voltages to the ESQ electrodes are placed inside the pressure vessel. The electrical structure of the power supply is schematically depicted in figure 2 . The master oscillator generates a $50 \mathrm{kV}$ sinusoidal voltage on the primary coil. Through inductive coupling a high voltage is induced on each of the 55 secondaries. Rectifier and filter circuits produce the desired dc voltage. The output voltage can be set by a reference from 0 to $3 \mathrm{MV}$ and can be adjusted to within $1 \%$. The maximum beam output power is $125 \mathrm{~kW}$ or $50 \mathrm{~mA}$ at $2.5 \mathrm{MeV}$ with an oscillator efficiency of $67 \%$. The primary coil has been installed inside the pressure tank and two-thirds of the secondary coils along with rectifier and filter circuits have been fabricated.

A multicusp source, which can deliver positive hydrogen ion beams with a monatomic fraction of higher than $90 \%{ }^{5}$, is mounted in the high voltage dome. Radiofrequency induction discharge provides reliable and long-life source operation. The pressure tank, which is about $6 \mathrm{~m}$ long and $2.4 \mathrm{~m}$ in diameter, and other parts were taken from a decommissioned accelerator: Future hospital-based ESQ-accelerators enclosed in a steel tank filled with $\mathrm{SF}_{6}$ could be more compact, approximately $3.5 \mathrm{~m}$ long. 


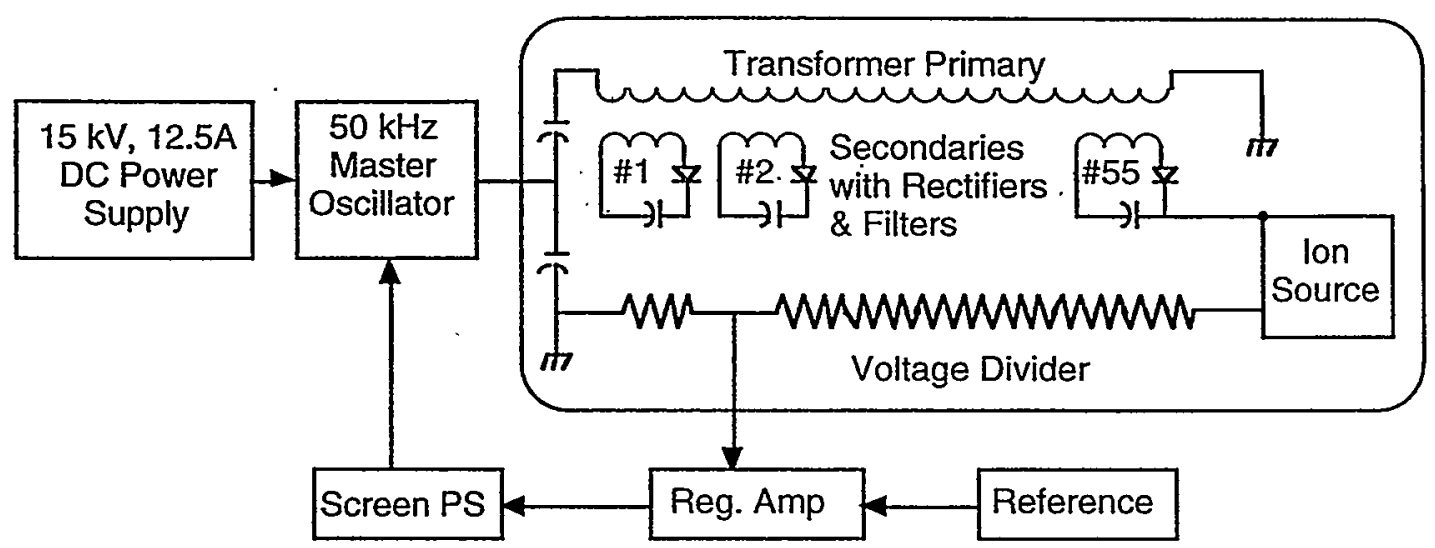

Fig. 2. Air-core transformer power supply.

\section{NEUTRON PRODUCTION TARGET}

A metallic lithium target for the production of neutron via the ${ }^{7} \mathrm{Li}(\mathrm{p}, \mathrm{n})^{7} \mathrm{Be}$ reaction at high beam currents requires efficient cooling. A $2.5 \mathrm{MeV}, 50 \mathrm{~mA}$ proton beam deposits a heat-load of $125 \mathrm{~kW}$ onto the target while the melting point of lithium is only $179 \mathrm{C}$. We have developed target designs which can handle such heat-loads and make it possible to utilize the accelerator's capability. A lithium layer, thick enough for the protons to loose enough of their energy to drop below the reaction threshold of $1.89 \mathrm{MeV}$, is deposited onto a metal cooling backing. Not making the layer thicker than necessary minimizes the heating of the lithium itself. The backing is convectively cooled through a large number of narrow cooling passages cut into the metal plate. Using finite element modeling the cooling panel geometry, such as size and spacing of the cooling channels, has been optimized. A prototype target panel was made out of aluminum and its thermal performance was tested at the Plasma Materials Test Facility at Sandia National Laboratory, Albuquerque, NM. Using a scanned electron beam a well-defined heat-load was deposited on the surface of the panel. Temperature measurements confirmed the modeling results ${ }^{6}$ indicating that the target can handle up to $600 \mathrm{~W} / \mathrm{cm}^{2}$. Two aluminum panels mounted in V-shape geometry at $30 \%$ in respect to the beam axis satisfy the cooling requirement. However, copper, although less preferable in terms of its radiation transport properties, has greatly superior mechanical properties. Finite element modeling has shown that significantly improved cooling can be achieved without creating undo thermal stresses when using Glidcop ${ }^{\mathrm{TM}}$ ( $99 \%$ copper content), a material which combines excellent thermal properties with high strength. The cross section of the target panel is shown in figure 3. Such a target can handle a heat-load of $1 \mathrm{~kW} / \mathrm{cm}^{2}$ while keeping the lithium temperature below $150 \mathrm{C}$. If the beam is spread over a circular area of about 13 $\mathrm{cm}$ in diameter, this target can handle a heat load of $125 \mathrm{~kW}$ as deposited by a $50 \mathrm{~mA}, 2.5$ $\mathrm{MeV}$ proton beam. Neutronics modeling has shown that target sizes up to $15 \mathrm{~cm}$ in diameter can be used without degrading the quality of the neutron beam and with only a small penalty in the total neutron flux. A further advantage of the target design is the small total amount of water in the target panel. 


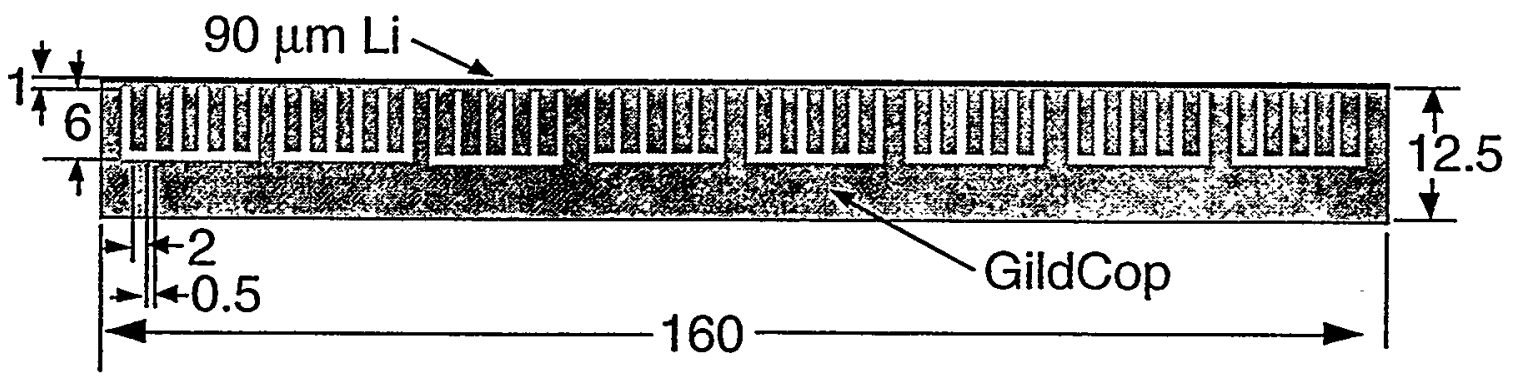

Fig. 3. Target cross section (units in $\mathrm{mm}$ ).

\section{NEUTRON BEAM MODELING}

The accelerator-based neutron source will produce a high neutron flux. In contrast to previous studies, which focussed on maximizing the epithermal neutron flux $\dot{x}^{7-9}$, this source provides the opportunity to optimize the quality of the neutron beam by improved moderation and filtering. In-air parameters are not sufficient for comparing and evaluating neutron beams for BNCT and in-phantom distributions must be used. For our studies we chose the dose to the midline of the brain as the figure-of-merit. Maximizing the dose to that point leads to the most penetrating neutron beams which, we believe, are best suited for the treatment of deeper seated brain tumors. Through modeling the radiation transport through moderator, reflector and filter assembly and head phantom the best energy

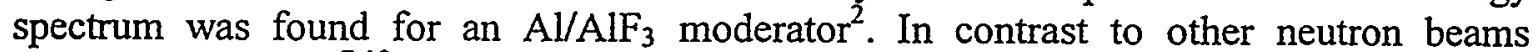
designed for $\mathrm{BNCT}^{7-10}$, the neutron current spectrum measured at the exit of the moderator displays a pronounced peak at about $15 \mathrm{keV}$ with a sharp falloff towards higher energies and a somewhat softer falloff towards lower energies ${ }^{2}$.

The different shape of the neutron energy spectrum translates into a remarkable increase in penetration. For calculating dose distributions in a head phantom boron concentrations, compound factors and RBE values from the BMRR dose calculation protocol were used in order to facilitate a direct comparison with the existing BMRR beam. In addition the same delimiter, $12 \mathrm{~cm}$ diameter opening and $13 \mathrm{~cm}$ thick, and distance from moderator surface to phantom were assumed ${ }^{2}$. Figure 4 shows tumor depth dose distributions along the beam axis calculated for two parallel-opposed beams. The dose calculations were based on $\mathrm{CT}$ data describing a specific head. The difference between the two beams is striking. Around the midline of the brain, in this case at a depth of $8 \mathrm{~cm}$, the modeled beam from the accelerator neutron source is able to deliver a roughly $50 \%$ higher dose than the BMRR beam.

Further improvements to the accelerator neutron beam are still possible. The peak in the energy spectrum can be made even narrower by using a different, less moderating reflector material, e.g., lead instead of $\mathrm{Al}_{2} \mathrm{O}_{3}$. In addition, the directionality can be improved by changing the delimiter and increasing the distance between moderator and patient. However, both of these changes lower the neutron flux and, therefore, the dose rate. The modeling results indicate that for the current design a proton beam current of 20 $\mathrm{mA}$ results in a treatment time of about $40 \mathrm{~min}$. 


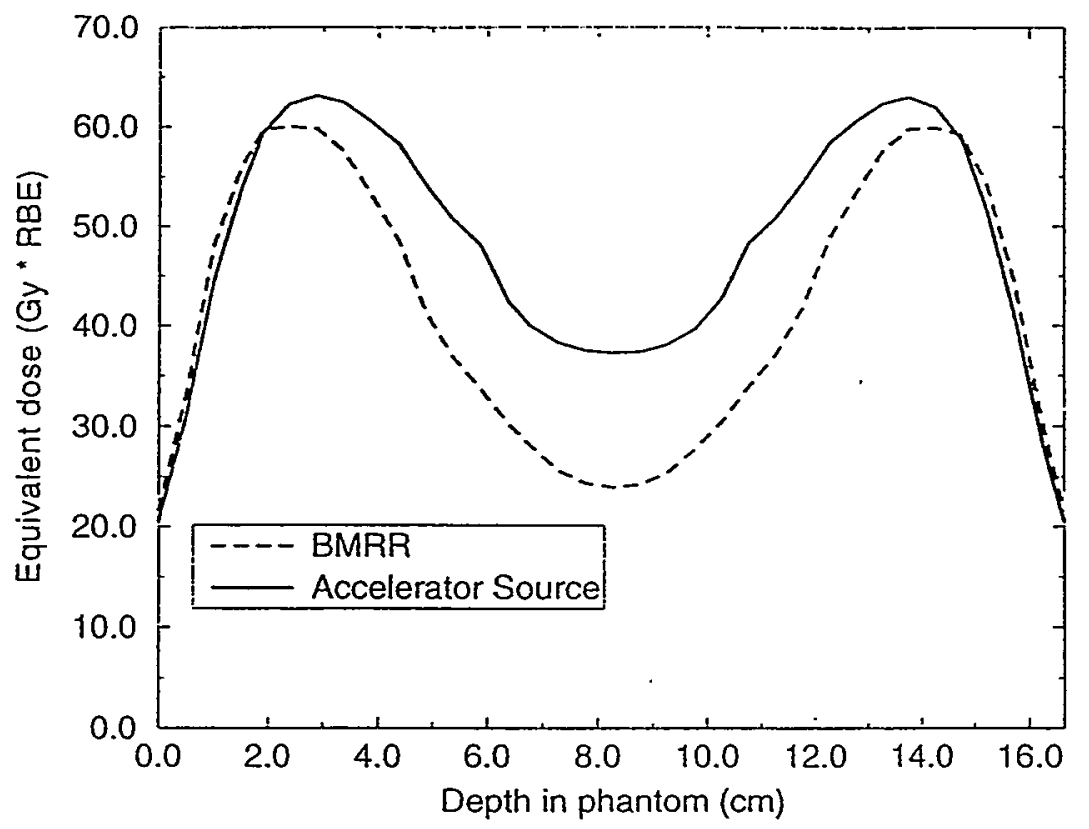

Fig. 4. Depth distributions of RBE-weighted tumor doses along the beam axis for the accelerator-produced beam in comparison to the BMRR beam.

\section{SUMMARY AND CONCLUSIONS}

Important progress has been made tówards the construction of an accelerator-based BNCT facility. The power supply for the high-current accelerator is nearing completion and a lithium target has been designed and tested which can handle the $125 \mathrm{~kW}$ heat-load deposited by a $2.5 \mathrm{MeV}, 50 \mathrm{~mA}$ proton beam. Our neutronics studies have demonstrated the importance of optimizing the neutron beam, in particular its energy spectrum, for maximizing the dose to deep seated tumors near the midline of the brain. For example, in cases in which the minimum target dose at BMRR is currently 21 to $25 \mathrm{RBE}-\mathrm{Gy}$ one may be able to deliver 32 to 37 RBE-Gy. Experience from a clinical GBM trial with fast neutrons suggests that a RBE-weighted dose of $30 \mathrm{RBE}-\mathrm{Gy}$ is needed to achieve a tumor control probability of $50 \%{ }^{11}$. This indicates that the tumor control probability may jump from almost zero for doses from 21 to $27 \mathrm{RBE}-\mathrm{Gy}$ to $75 \%$ and higher for doses above 32 RBE-Gy which are obtainable with a more penetrating beam.

\section{REFERENCES}

1. Ludewigt BA. Clinical Requirements and Accelerator Concepts for BNCT. Proceedings of the Particle Accelerator Conference 1997, Vancouver, BC, Canada, May 1997.

2. Bleuel DL, Donahue RJ, Ludewigt BA, Vujic J. Med. Phys. 1998; 25(9):1725-1734. 
3. Kwan JW, Andersson OA, Reginato LL, Vella MC, Yu SS. A $2.5 \mathrm{MeV}$ electrostatic quadrupole DC-accelerator for BNCT applications. Nucl. Instrum. Methods Phys. Res. 1995; B 99:710-712.

4. Reginato LL, Ayers J, Johnson R, Peters C, Steveson R. Designing power supplies for $2.5 \mathrm{MeV}, 100 \mathrm{~mA}$ d.c. for BNCT. Proceedings of the $14^{\text {th }}$ International Conference on the Application of Accelerators in Research and Industry, Denton, Texas, November, 1996 (AIP Press, New York, 1997), Vol. II:1313-1315.

5. Leung KN. Ion Sources for High Purity Ions. Proceedings of the $14^{\text {th }}$ International Conference on the Application of Accelerators in Research and Industry, Denton, Texas, November, 1996 (AIP Press, New York, 1997), Vol. II:1203-1205.

6. Ludewigt BA, Chu WT, Donahue RJ, Kwan JW, Phillips TL, Reginato LL, Wells RP. An Epithermal Neutron Source for BNCT based on an ESQ Accelerator. Proceedings of the Topical Meeting on Nuclear Applications of Accelerator Technology, Albuquerque, NM, Nov. 1997:489-494.

7. Wang CK, Bleu TE, Gahbauer R. A neutronic study of an accelerator-based neutron irradiation facility for boron neutron capture therapy. Nucl. Technol. 84, 1989: 93107.

8. Yanch JC, Zhou XL, Shefer RE, Klinkowstein RE. Accelerator-based epithermal neutron beam design for neutron capture therapy. Med. Phys. 1992; 19:709-721.

9. Allen DA, Beynon TD. A design study for an accelerator-based epithermal neutron beam for BNCT. Phys. Med. Biol. 1995; 40:807-821.

10. Becker GK, Harker YD, Miller LG, Anderl RA, Wheeler FJ. Neutron spectrum measurements in the aluminum oxid filtered beam facility at the Brookhaven Medical Research reactor. In: Neutron Beam Development and Performance for Neutron Capture Therapy. Eds. O. Harling, J.A. Bernard, R.G. Zamenhof. Plenum Press, New York, 1990.

11. Laramore GE, Wheeler FJ, Wessol DE, Stelzer KJ, Griffin TW. A BNCT Tumor Control Curve for Malignant Glioma from Fast Neutron Therapy Data: Implications for Beam Delivery and Compound Selection. In: Advances in Neutron Therapy, Elsevier 1997; Vol II:580-587. 